\title{
Properties of Concrete Containing Recycled Fine Aggregate and fly ash
}

\author{
$\underline{\text { S. F. U. Ahmed }}$ \\ Dept. of Civil Engineering. Curtin University.
}

\begin{abstract}
Synopsis: This paper reports the properties of concrete containing recycled fine aggregate (RFA) and fly ash (FA) obtained from local source in Perth, Western Australia (WA). This study is consisted of two parts. In the first part, the properties of concrete containing 25, 50, 75 and $100 \%$ (by wt.) replacement of natural fine aggregate (NFA) with RFA are considered. In the second part, the effect of class $F$ fly ash as partial replacement of cement on the properties of recycled concretes containing 25\% and 50\% RFA are evaluated. The fly ash is used as $30 \%$ and $40 \%$ replacement of cement. The properties of concrete evaluated are the compressive strength, indirect tensile strength, flexural strength and water absorption. All properties are measured at 7, 28 and 56 days. The results show that, better compressive, tensile and flexural strength of concrete can be obtained in recycled aggregate concretes containing upto $50 \%$ RFA as partial replacement of NFA. However, in the case of recycled aggregate concretes containing $30 \%$ and $40 \%$ fly ash the compressive strength is increase at 56 days and both compressive strength and tensile strengths are decreased at early ages. The flexural strength is increased in recycled aggregate concrete containing fly ash. It is observed that the water absorption is increased as RFA content increased. It is also observed that the water absorption is decreased significantly in recycled aggregate concretes containing fly ash at 56 days.
\end{abstract}

Keywords: recycled fine aggregate, fly ash, compressive strength, tensile strength, flexural strength, water absorption.

\section{Introduction}

Concrete is one of the most abundantly used construction materials on the Earth and it consists of cementitious materials, water, coarse and fine aggregate. Both coarse and fine aggregates occupy approximately $75 \%$ to $80 \%$ of concrete and it is expected that the demand of aggregates will be doubled in the next 30 years due to increased urbanisation and infrastructures growth worldwide [1]. Yet there are worrying signs indicating that the shortage of aggregates sources are imminent especially in large urban areas and this can cause scarcity problems in the future. On the other hand, vast amount of construction and demolition (C\&D) wastes are generated due to increased construction activities and these C\&D wastes are generally sent for landfill. It has been estimated that 1.5 million tonnes of C\&D waste was generated in Perth metropolitan area in 2000 [2]. This waste was subsequently sent to landfill, accounting for almost $55 \%$ by weight. Therefore, utilization of C\&D wastes as replacement for virgin aggregates should be a viable option for concrete industry. The use of recycling aggregates processed from C\&D wastes is one of possible solutions which have been thoroughly researched worldwide.

Extensive research have been conducted to evaluate the properties of concrete containing recycled coarse aggregates but very limited research have been conducted to examine the effect of recycled fine aggregate (RFA) on properties of concrete [3-6]. Khatib [6] reported only 10\% reduction in 28-day compressive strength of concrete containing 100\% RFA, while Evangelista [4] observed negligible effect on the compressive strength of concrete containing RFA of $30 \%$ or less. In all of the studies above the RFA is obtained from controlled sources like crushing and grinding of aggregates in laboratory, different known grade of old concrete, etc. However, in practice it is difficult and not cost effective for the manufacturer of recycled aggregates to sort different types of demolished concrete. Most often they combined different C\&D wastes together. Conflicting results in the above research is also due to difference sources of RFA.

Fly ash is the by product of coal fired power plant and the disposal of this material creates another environmental problem. The effects of fly ash on concrete are well established. Utilizing fly ash as partial replacement of cement has environmental benefits, reduces landfill demands, reduces concrete costs and improves concrete properties [7]. 
This study is conducted to evaluate the properties of concrete containing RFA available locally in Perth, WA and class F fly ash. In part A, the effect of various replacement levels of RFA on the compressive strength, tensile strength, flexural strength and water absorption of recycled concretes is evaluated. The optimum RFA content(s) in terms of better or similar properties of those concretes containing NFA are used in part B where the effect of $30 \%$ and $40 \%$ fly ash as partial replacement of cement in those concretes are evaluated.

\section{Research significance}

To the best of author's knowledge, no research is reported on the properties of concrete containing combined RFA and fly ash. The contents and properties of RFA vary considerably if the source is from mixed C\&D wastes. In most reported studies on recycled aggregate concretes, the RFA is obtained from known source, such as concrete of known compressive strengths, demolished concrete as the only source of material, etc. However, in reality C\&D wastes are consisted of demolished concretes of various strengths, demolished masonry structures, and other demolished RC structures. In order to promote the locally manufactured RFA in the concrete industry the properties of concretes containing RFA need to be studied. The partial replacement of cement by fly ash in recycled aggregate concretes makes the concrete more green which will be of great interest to the construction industry.

\section{Experimental program}

\subsection{Materials}

General purpose Portland cement is used in all mixes. The fly ash used in this study is class $\mathrm{F}$ fly ash and is obtained from Collie power station in WA. The recycled fine aggregate is obtained from a local recycling plant in Perth, WA. The RFA is washed thoroughly and dried afterwards to maintain the saturated surface dry (SSD) condition. Natural coarse aggregate (NCA) of $10 \mathrm{~mm}$ and $20 \mathrm{~mm}$ sizes are used in this study. The properties of recycled and natural fine aggregates are shown in Table 1 . Sieve analysis of RFA and NFA is also conducted and is shown in Fig. 1. It is observed that the RFA used in this study met the requirements specified in Australian standard 2758.1 - 1998 as shown in Figure 1.

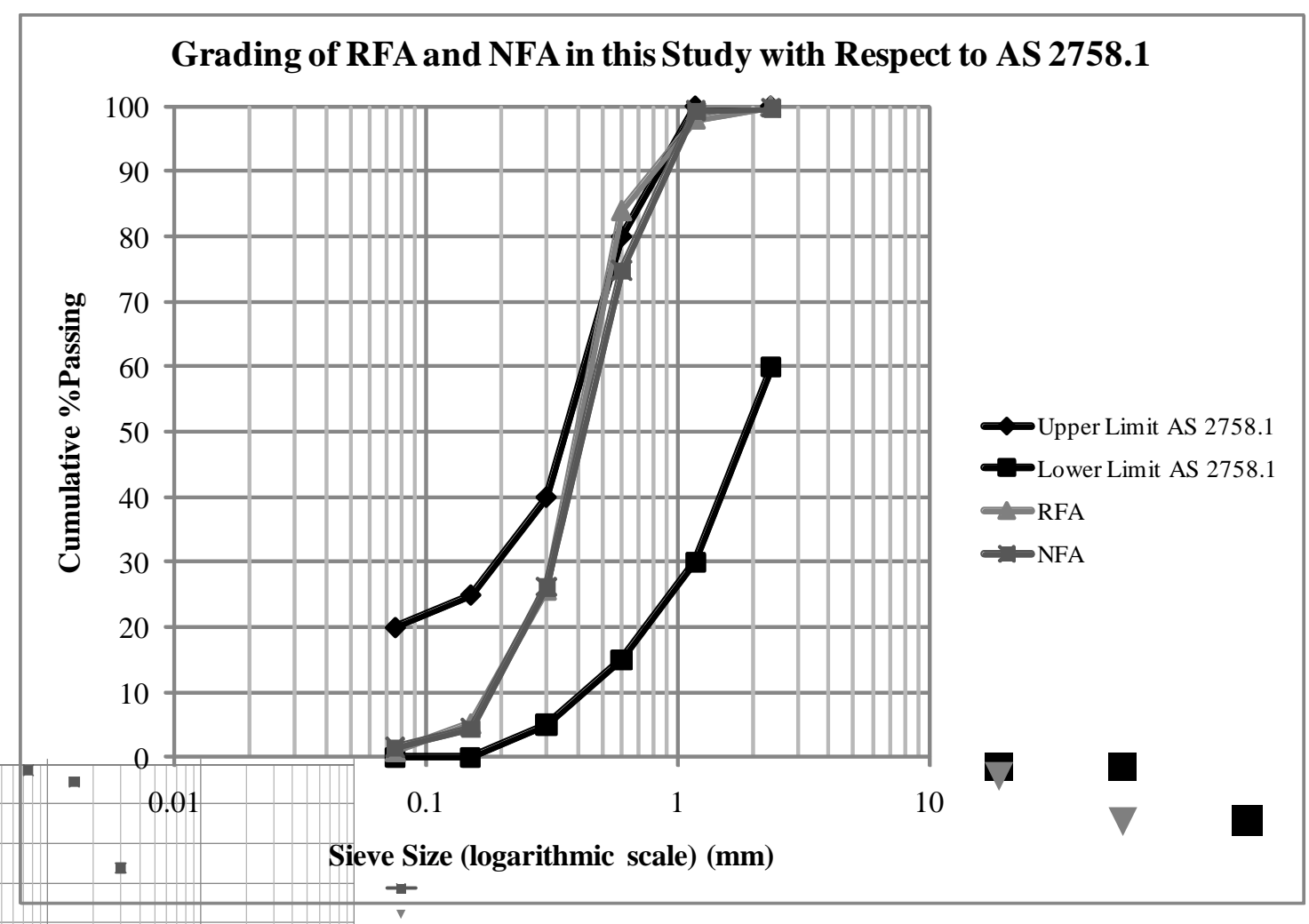

Figure 1: Grading of RFA and NFA with Respect to AS 2758.1 


\subsection{Mix Proportions}

In total nine series of mixes are considered in this study. Five series are considered in part A of this study to evaluate the effect of different replacement levels of NFA with RFA. First series is the control mix where both NCA and NFA are considered. While in remaining four series the RFA are added at different replacement levels such as at $25 \%, 50 \%, 75 \%$ and $100 \%$ of NFA. In part B, the effect of $30 \%$ and $40 \%$ fly ash used as partial replacement of cement on the properties of recycled concretes containing $25 \%$ and $50 \%$ RFA are evaluated. Details of the experimental program can be seen in Table 2. The mix proportions of all the mixes are shown in Table 3.

Table 1: Water Absorption and Bulk Density of RFA and NFA

\begin{tabular}{|c|c|c|}
\hline Properties measured & NFA & RFA \\
\hline Water Absorption (\%) & 1.16 & 2.61 \\
\hline Uncompacted Bulk Density $\left(\mathrm{kg} / \mathrm{m}^{3}\right)$ & 1498 & 1607 \\
\hline Compacted Bulk Density $\left(\mathrm{kg} / \mathrm{m}^{3}\right)$ & 1634 & 1734 \\
\hline
\end{tabular}

Table 2: Detailed Experimental Program

\begin{tabular}{|c|c|c|c|c|c|c|}
\hline Part & Series & NCA (\%) & NFA (\%) & RFA(\%) & $\begin{array}{c}\text { Fly ash } \\
\text { (\%) }\end{array}$ & Mix designation \\
\hline \multirow{4}{*}{$A$} & 1 & 100 & 100 & 0 & 0 & Control (0\% RFA) \\
\cline { 2 - 7 } & 2 & 100 & 75 & 25 & 0 & $25 \%$ RFA \\
\cline { 2 - 7 } & 3 & 100 & 50 & 50 & 0 & $50 \%$ RFA \\
\cline { 2 - 7 } & 4 & 100 & 25 & 75 & 0 & $75 \%$ RFA \\
\cline { 2 - 7 } & 5 & 100 & 0 & 100 & 0 & $100 \%$ RFA \\
\hline \multirow{3}{*}{ B } & 6 & 100 & 75 & 25 & 30 & $25 \%$ RFA+30\% fly ash \\
\cline { 2 - 7 } & 7 & 100 & 75 & 25 & 40 & $25 \%$ RFA+40\% fly ash \\
\cline { 2 - 7 } & 8 & 100 & 50 & 50 & 30 & $50 \%$ RFA+30\% fly ash \\
\cline { 2 - 7 } & 9 & 100 & 50 & 50 & 40 & $50 \%$ RFA+40\% fly ash \\
\hline
\end{tabular}

Table 3: Mix Proportions

\begin{tabular}{|c|c|c|c|c|c|c|}
\hline \multirow[t]{2}{*}{ Mix designation } & \multicolumn{6}{|c|}{ Mix (In kg/m3) } \\
\hline & $\begin{array}{l}\text { Cement } \\
\text { content }\end{array}$ & $\begin{array}{l}\text { Water } \\
\text { content }\end{array}$ & Fly ash & $\begin{array}{l}\text { Coarse } \\
\text { aggregate }\end{array}$ & NFA & RFA \\
\hline Control ( $0 \%$ RFA) & \multirow{5}{*}{430} & \multirow{9}{*}{194} & \multirow{5}{*}{ - } & \multirow{9}{*}{1038} & 727 & - \\
\hline $25 \%$ RFA & & & & & 545 & 182 \\
\hline $50 \%$ RFA & & & & & 363 & 363 \\
\hline $75 \%$ RFA & & & & & 182 & 545 \\
\hline $100 \%$ RFA & & & & & 0 & 727 \\
\hline $25 \%$ RFA $+30 \%$ fly ash & 301 & & 129 & & 545 & 182 \\
\hline $25 \%$ RFA $+40 \%$ fly ash & 258 & & 172 & & 545 & 182 \\
\hline $50 \%$ RFA $+30 \%$ fly ash & 301 & & 129 & & 363 & 363 \\
\hline $50 \%$ RFA+40\% fly ash & 258 & & 172 & & 363 & 363 \\
\hline
\end{tabular}




\subsection{Casting, Curing and Testing}

The compressive strength, indirect tensile strength, flexural strength and water absorption of concretes containing RFA were measured at three different ages (7-day, 28-day and 56-day) with the exception of flexural strength (only 28-day and 56-day) in each series to evaluate the effect of RFA on the properties of concrete. Slump test was done immediately after mixing to measure the workability of each mix. At least three specimens were cast and tested in each series. All specimens were water cured until the day before the test date. The compressive strength test was carried out on $100 \times 200 \varnothing \mathrm{mm}$ cylinders and the indirect tensile strength was determined on $150 \times 300 \varnothing \mathrm{mm}$ cylinders. As for modulus of rupture, $100 \mathrm{x}$ $100 \times 400 \mathrm{~mm}$ prism was tested. The $100 \times 200 \varnothing \mathrm{mm}$ cylinders were cut into four slices and were used in water absorption test. All tests were conducted in accordance with relevant Australian standard.

\section{Results and discussions}

\subsection{Compressive Strength}

The development of compressive strengths of concretes containing RFA at 7, 28 and 56 days is shown in Fig. 2. The results show that the compressive strength of concretes containing RFA of upto $50 \%$ is increased with increase in RFA content and this is observed at all ages except at 56 days where a slight reduction is observed. However, significant reduction in the compressive strength of concretes containing $75 \%$ and $100 \%$ RFA is observed at all ages. The reductions are $13 \%$ and $22 \%$ at 28 -day and 56 -day, respectively of concrete containing 100\% RFA. This is also consistent with the results previously obtained from Khatib [6].

Rinsing the RFA is one of the reasons for slight improvement of compressive strength of concrete containing $25 \%$ and 50\% RFA compared to the control. Boltryk [8] stated that the rinsing of RFA improves the strength of aggregate-cement paste interfacial zone and cohesion between aggregates. Another reason for the maintenance of better compressive strength is the extra cement attached into it. Katz [9] proposed that the extra cement content in RFA can be as high as 25\%. RFA is also more angular due to grinding and crushing. This improves the friction resistance of the aggregate that in turn increases the compressive strength of concrete which depends heavily on the strength of its aggregate. However, as more RFA is added to replace the virgin one, this leaves more voids and pores in the concrete, reducing the compressive strength as well. The amount of voids in concrete is also influenced by the porosity of the aggregates. The RFA is more porous than NFA due to high amount of old mortars. Therefore, high amount of RFA in concrete mix would eventually reduce its compressive strength and this is observed in this study as well.

The effect of fly ash on the development of compressive strength of recycled concretes containing RFA can also be seen in Fig. 2. The reduction of compressive strength of recycled concretes containing $25 \%$ and $50 \%$ RFA at early ages such as at 7 and 28 days is observed when $30 \%$ and $40 \%$ fly ash are use as partial replacement of cement in those concretes. However, at 56 days no such reduction is observed, rather slight increase in compressive strengths is observed in those concretes. This could be attributed to the slow pozzolanic reaction involved in concrete containing moderate amount of fly ash. The long term strength gain of fly ash concretes is reported by many researchers. 


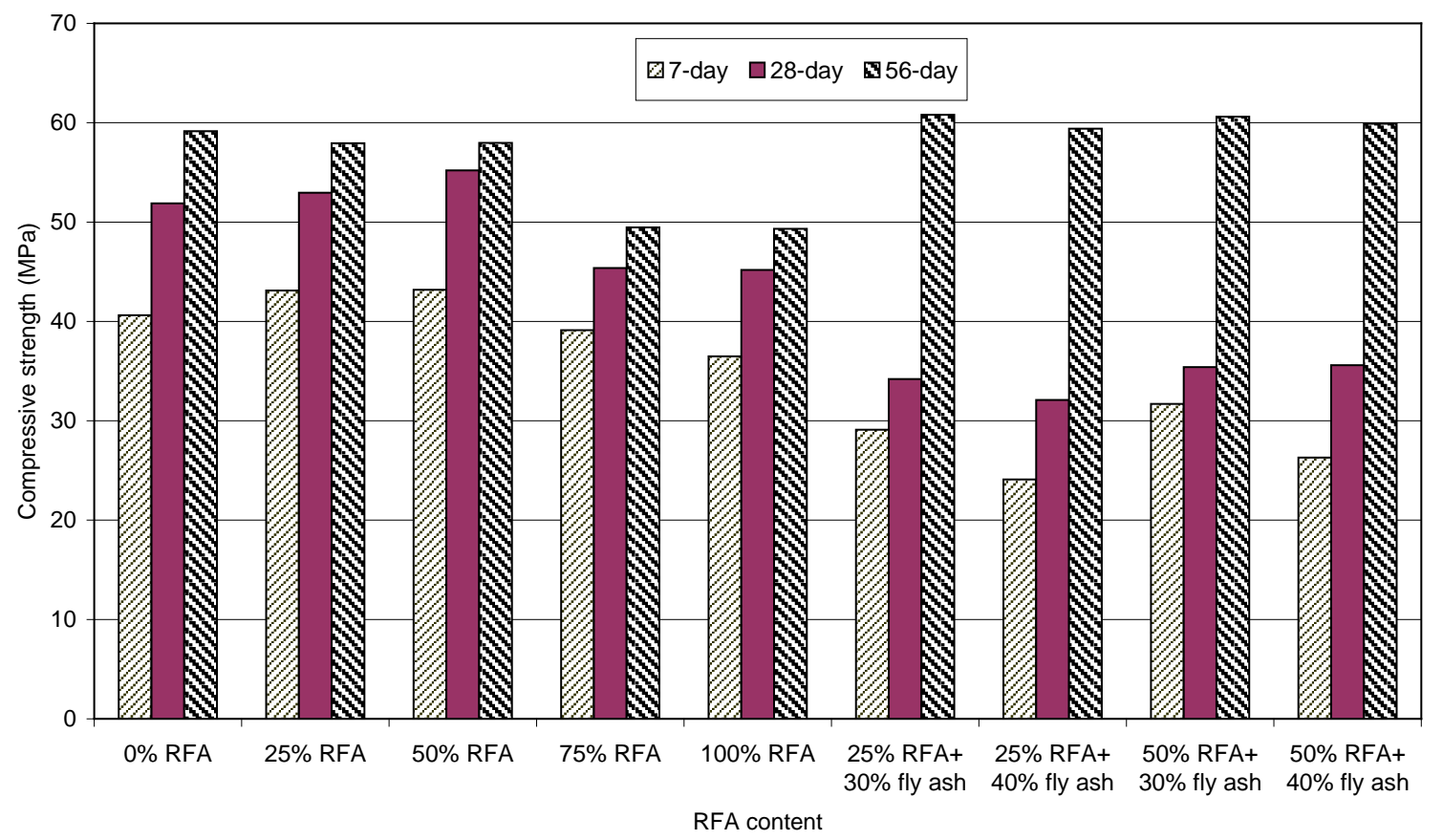

Figure 2 Effect of RFA and fly ash on compressive strengths of recycled concretes

\subsection{Indirect Tensile Strength}

The development of indirect tensile strengths of all mixes at 7,28 and 56 days is shown in Fig. 3 . Generally, the splitting strength of recycled concretes reduces with increase in RFA contents at all ages except the concretes containing the RFA content of upto $50 \%$ at 7 days where an increase in tensile strength is observed. However, the rate of reduction is not as high as observed in concretes containing more than 50\% RFA. The effect of fly ash as partial replacement of cement on the tensile strength of concretes containing RFA is also shown in Fig. 3. It can be seen that the tensile strength of recycled concretes containing $25 \%$ and $50 \%$ RFA is decreased due to the replacement of $30 \%$ cement with fly ash. At higher replacement level, such as at $40 \%$ fly ash, two completely opposite trends are observed; the tensile strength is decreased in concrete containing 25\% RFA where as the tensile strength is increased in concrete containing 50\% RFA at all ages.

In Table 4 the comparison of theoretical prediction of indirect tensile strength of recycled concretes with that measured in the experiments are shown. It can be seen that the theoretical values according to AS $3600-2009$ are lower than the measured values. This indicates that the current formula to predict the tensile strength of concrete in AS $3600-2009$ is conservative for concrete containing RFA. However, in the case of recycled concretes containing both RFA and fly ash better correlation can be observed between the measured and theoretical values. 


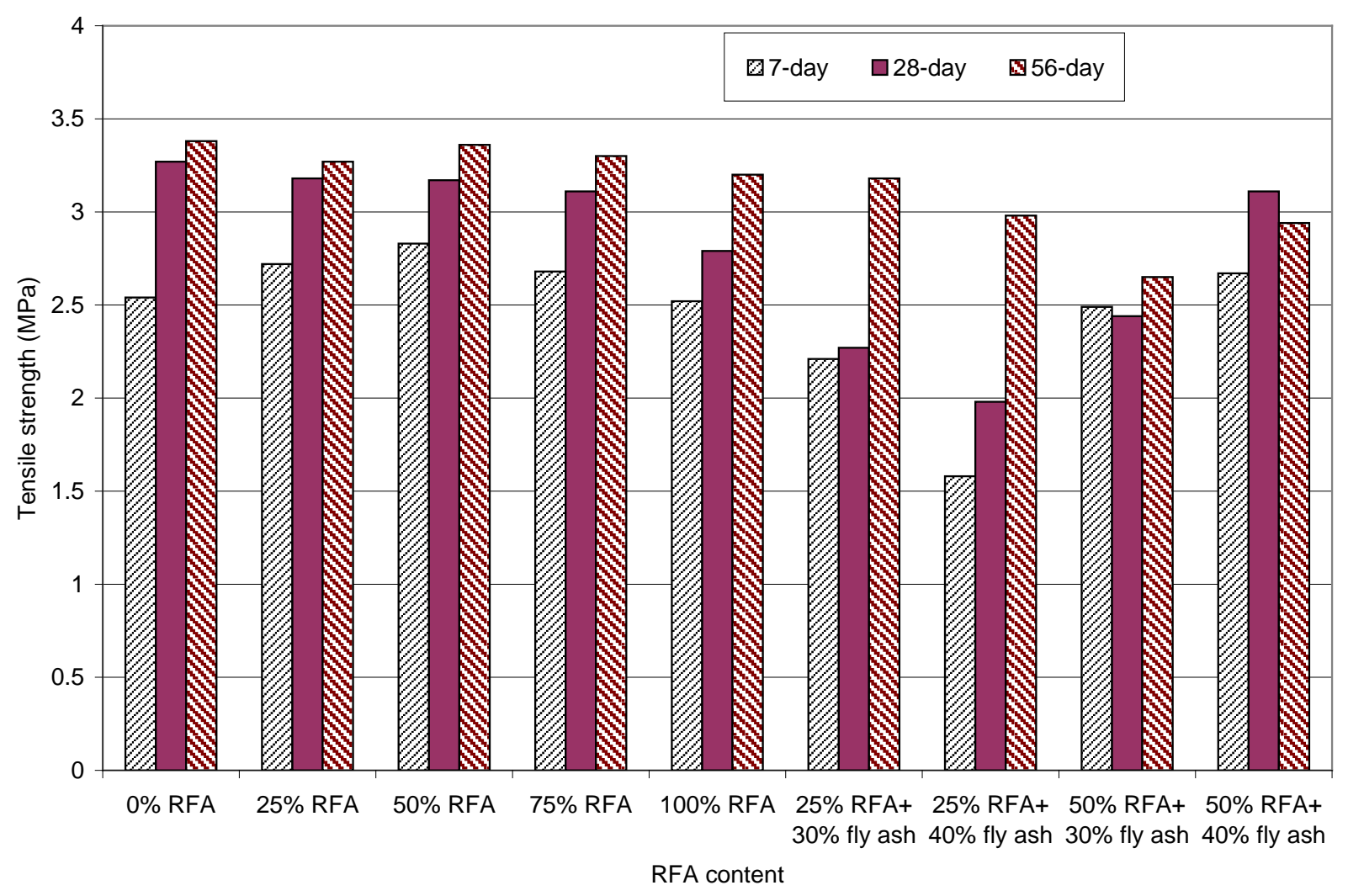

Figure 3 Effect of RFA and fly ash on indirect tensile strengths of recycled concretes

\subsection{Flexural Strength}

The flexural strength of all mixes at 28 and 56 days is presented in Fig. 4. Similar to the compressive and the tensile strengths, the flexural strength of concrete containing RFA increases as the RFA contents increases upto $50 \%$ and it decreased at higher contents of RFA such as at $75 \%$ and $100 \%$. The effect of fly ash as partial replacement of cement on flexural strength of concretes containing RFA is also shown in Fig. 4. It can be seen that the flexural strength of recycled concretes is increased due to the replacement of $30 \%$ cement with fly ash. At higher replacement level, such as $40 \%$ fly ash, two completely opposite trends are also observed similar to that of the tensile strength; the flexural strength is decreased in concrete containing $25 \%$ RFA where as it is increased in concrete containing 50\% RFA at all ages.

In Table 5 the comparison of the theoretical prediction of flexural strength of recycled concretes with that measured in the experiments are shown. It can be seen that unlike indirect tensile strengths the theoretical flexural strength values according to AS $3600-2009$ are slightly lower than the measured values, but overall the measured and the predicted values exhibit good correlation. This indicates that the current approximation formula in AS $3600-2009$ for flexural strength of concrete can be used for concrete containing RFA. However, it is more conservative for concretes containing both RFA and fly ash. 
Table 4: Comparison of Theoretical and Measured Indirect Tensile Strengths

\begin{tabular}{|c|c|c|c|c|}
\hline & Mix & $\begin{array}{c}\text { Theoretical } \\
\text { Indirect } \\
\text { Tensile Strength }\end{array}$ & $\begin{array}{c}\text { Measured Indirect } \\
\text { Tensile Strength }\end{array}$ & $\begin{array}{c}\text { Ratio of } \\
\text { Measured vs } \\
\text { Theoretical }\end{array}$ \\
\cline { 2 - 4 } & Days & MPa & MPa & 1.26 \\
\hline Control (0\% RFA) & 28 & 2.59 & 3.27 & 1.28 \\
\hline $25 \%$ RFA & 28 & 2.49 & 3.18 & 1.19 \\
\hline $50 \%$ RFA & 28 & 2.67 & 3.17 & 1.38 \\
\hline $75 \%$ RFA & 28 & 2.42 & 3.34 & 1.15 \\
\hline $100 \%$ RFA & 28 & 2.42 & 2.79 & 0.97 \\
\hline $25 \%$ RFA+30\% fly ash & 28 & 2.34 & 2.27 & 1.00 \\
\hline $25 \%$ RFA+40\% fly ash & 28 & 1.97 & 1.98 & 1.03 \\
\hline $50 \%$ RFA+30\% fly ash & 28 & 2.38 & 2.44 & 1.26 \\
\hline $50 \%$ RFA+40\% fly ash & 28 & 2.39 & 3.01 & \\
\hline
\end{tabular}

Table 5: Comparison of Theoretical and Measured Flexural Strengths

\begin{tabular}{|c|c|c|c|c|}
\hline \multirow{2}{*}{ Mix } & Age & $\begin{array}{c}\text { Theoretical } \\
\text { Flexural } \\
\text { Strength }\end{array}$ & $\begin{array}{c}\text { Measured Flexural } \\
\text { Strength }\end{array}$ & $\begin{array}{c}\text { Ratio of Measured } \\
\text { vs Theoretical }\end{array}$ \\
\cline { 2 - 4 } & Days & MPa & MPa & 1.13 \\
\hline Control (0\% RFA) & 28 & 4.32 & 4.77 & 1.15 \\
\hline $25 \%$ RFA & 28 & 4.16 & 4.86 & 1.09 \\
\hline $50 \%$ RFA & 28 & 4.46 & 4.03 & 1.00 \\
\hline $75 \%$ RFA & 28 & 4.04 & 3.97 & 0.98 \\
\hline $100 \%$ RFA & 28 & 4.03 & 5.36 & 1.52 \\
\hline $25 \%$ RFA+30\% fly ash & 28 & 3.51 & 4.68 & 1.58 \\
\hline $25 \%$ RFA+40\% fly ash & 28 & 2.96 & 5.30 & 1.48 \\
\hline $50 \%$ RFA+30\% fly ash & 28 & 3.57 & 4.38 & 1.22 \\
\hline $50 \%$ RFA+40\% fly ash & 28 & 3.58 & & \\
\hline
\end{tabular}




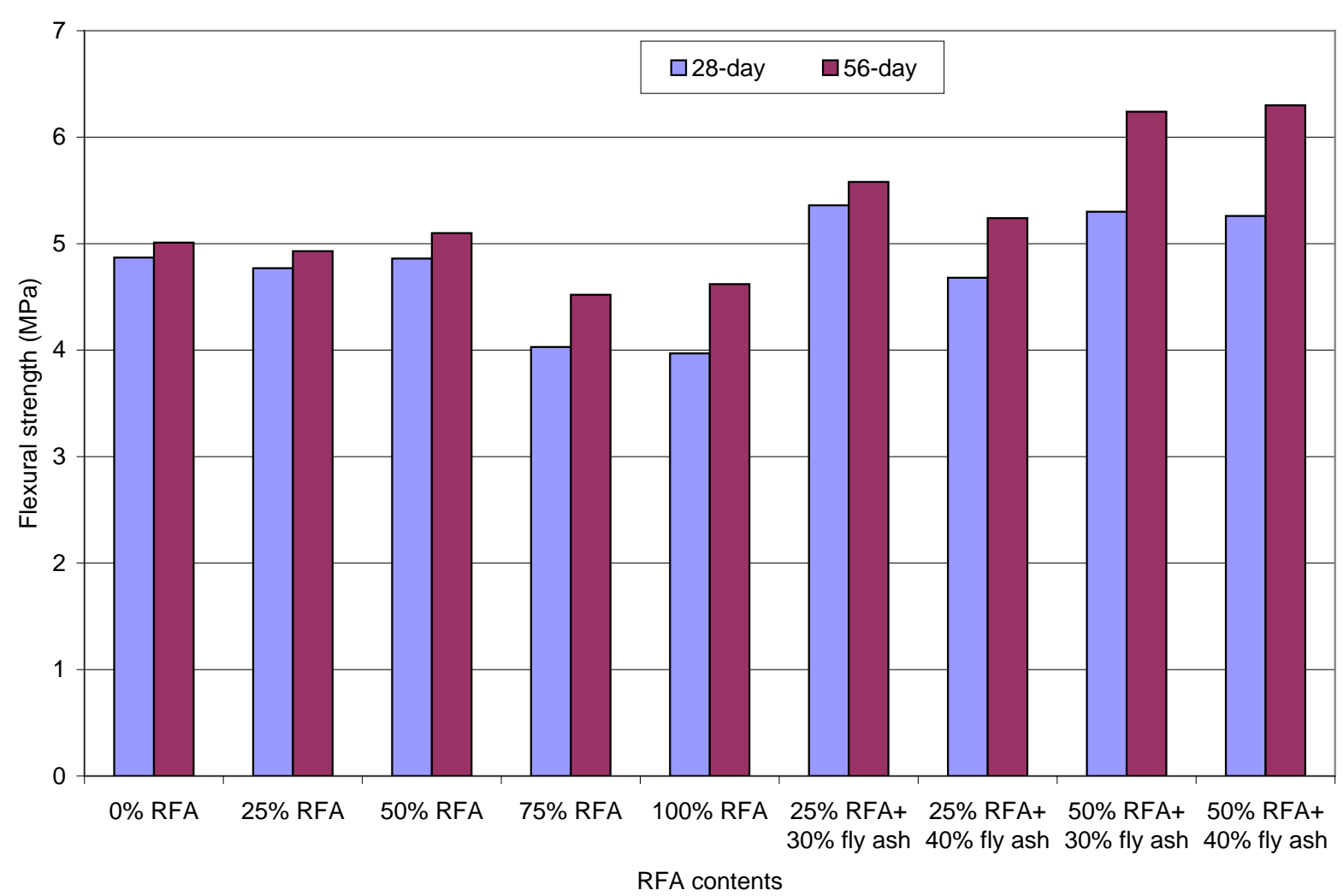

Figure 4 Effect of RFA and fly ash on flexural strengths of recycled concretes

\subsection{Water Absorption}

The water absorption test results of all mixes at 7, 28 and 56 days is shown in Fig. 5 . It is observed in the figure that the water absorption of concretes containing RFA increases with increase in RFA contents. This is caused by higher water absorption of RFA itself compared to NFA observed in this study. The RFA also has higher particle surface area due to adherence of old mortars on it for equal volume of aggregates [10]. High water absorption values also indicate higher porosity of concrete which is caused by the porous recycled aggregate itself as well as porous $\mathrm{C}-\mathrm{S}-\mathrm{H}$ structure due to inadequate free water content. However, the scenario changes when fly ash is added in the recycled concretes. It can be seen in Fig. 5 that the water absorptions of recycled concretes containing $30 \%$ and $40 \%$ fly ash changed significantly after 28 and 56 days of curing. This can be attributed to the pozzolanic and particle packing effects of fly ash in those concretes. The formation of dense microstructure through the formation of secondary C-S-H gel in the matrix and interfacial transition zone (ITZ) between aggregates and matrix in fly ash concretes is reported by many researchers.

From the results it can be seen that the combined use of fly ash and RFA in concrete is feasible as long as the reductions in strength are accounted for in the design process. Concrete mixes with RFA replacements of $75 \%$ and $100 \%$ are however found to be unpractical due to poor strength. For 'green concrete' to become widely accepted as a substitute for conventional concrete quality control is essential to ensure consistent and predictable capacity.

It is recommended that further study is necessary considering other variables such as w/c ratios, varying fly ash contents and the use of admixtures. Further study can also be conducted to test sample at ages beyond 56 days to investigate the long term influence of fly ash on concrete containing RFA. It is also recommended to conduct an optimisation study to determine optimum RFA and fly ash contents and optimum mix proportions. 


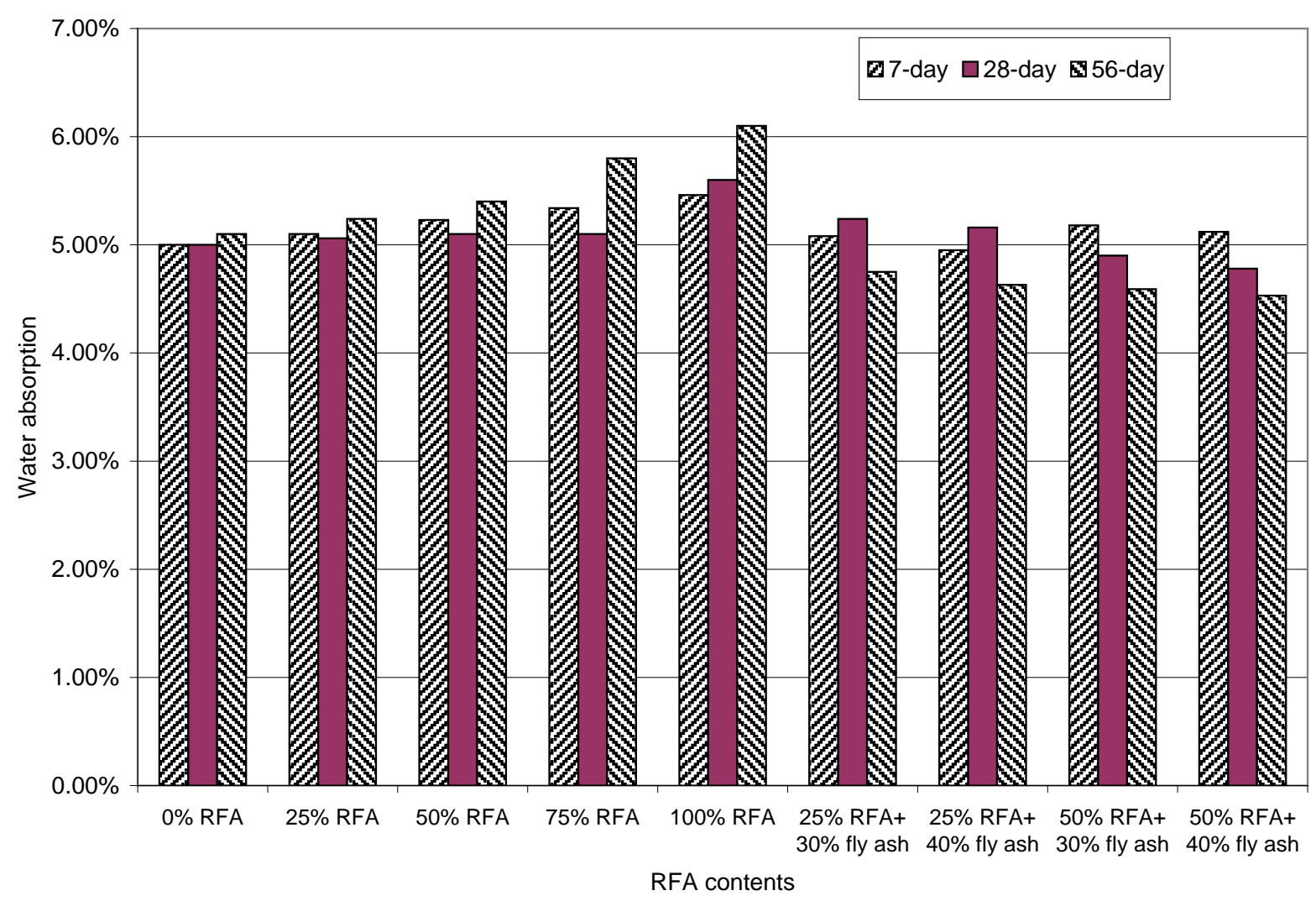

Figure 5 Effect of RFA and fly ash on water absorption of recycled concretes

\section{Conclusions}

Based on the results of this study, using the materials and ranges of variables taken into account, the following conclusion can be drawn for properties of concrete containing RFA and fly ash:

1. The concrete containing RFA contents of upto 50\% exhibited similar or slightly better compressive strength, indirect tensile strength and flexural strength at all ages.

2. At high RFA contents, such as at $75 \%$ and $100 \%$, the above strengths decreased significantly.

3. The water absorption of concrete increases with increase in RFA contents.

4. The partial replacement of cement with $30 \%$ and $40 \%$ fly ash in the recycled aggregate concretes exhibited improvement in compressive strength, flexural strength and water absorption at 56 days.

5. The use of fly ash as partial replacement of cement in concretes containing RFA does not improve the concrete properties at all ages.

6. Based on the limited variability and range of experimental data, the prediction equation recommended in AS 3600 for estimating indirect tensile and flexural strength based on compressive strength appears to be applicable for recycled aggregate concrete containing RFA and fly ash.

\section{ACKNOWLEDGEMENTS}

Author acknowledges All Earth Group for donating the recycled aggregates and Fly ash Australia for donating the class F fly ash. Grateful acknowledgement is also due to final year project students Mr. Evan Triendy Buntoro and Mrs. Ma Vanessa De La Fuente for their assistance in casting and testing of specimens in this study. 
1. EcoSmart. Enviromental impact: cement production and the CO2 challenge. 2004. http://www.ecosmartconcrete.com/enviro_cement.cfm (accessed January 12, 2010).

2. Wastenet. Construction and demolition waste. 2009. http://www.wastenet.net.au/information/streams/cons_demo (accessed August 26, 2009).

3. Evangelista, L., and J. de Brito. "Mechanical behaviour of concrete made with fine recycled concrete aggregates." Cement and Concrete Composites, 2007: 397-401.

4. Khatib, J.M. "Properties of concrete incorporating fine recycled aggregate." Cement and Concrete Research 35, 2005: 763-769.

5. Kou, S.C., and Poon, C.S. "Properties of self-compacting concrete prepared with coarse and fine recycled concrete aggregates." Cement \& Concrete Composite 31, 2009: 622-627.

6. Kou, S.C. and Poon, C.S. Properties of concrete prepared with crushed fine stone, furnace bottom ash and fine recycled aggregate as fine aggregate, Construction and Building Materials 23, 2009: 2877-2886.

7. Ravina, D. and Mehta, P.K. (1986) Properties of fresh concrete containing large amounts of fly ash. Cement and Concrete Research, 16(2): 227-238.

8. Boltryk, M., Dorota M., and Edyta P. Basic technical properties of recycled aggregate concrete. www.vgtu.It/leidiniai/leidykla/MBM_2007/1pdf/Boltryk_Mal2.pdf (accessed November 3, 2009).

9. Katz, A. "Properties of concrete made with recycled aggregate from partially hydrated old concrete." Cement and Concrete Research 33, 2003: 703-711.

10. Dapena, E., Alaejos, P., Lobet, A. and Perez, D. Effect of recycled sand content on characteristics of mortars and concretes, ASCE journal of materials in civil engineering, 23(4), 2011: 414-422. 